\title{
Somatic Translocation: A Novel Mechanism of Granule Cell Dendritic Dysmorphogenesis and Dispersion
}

\author{
Brian L. Murphy ${ }^{1,4}$ and Steve C. Danzer ${ }^{1,2,3,4}$ \\ ${ }^{1}$ Department of Anesthesia, Cincinnati Children's Hospital Medical Center, Cincinnati, Ohio 45229, Departments of ${ }^{2}$ Anesthesia and ${ }^{3}$ Pediatrics, University \\ of Cincinnati, Cincinnati, Ohio 45221, and ${ }^{4}$ Program in Neuroscience, University of Cincinnati, Cincinnati, Ohio 45229
}

Pronounced neuronal remodeling is a hallmark of temporal lobe epilepsy. Here, we use real-time confocal imaging of tissue from mouse brain to demonstrate that remodeling can involve fully differentiated granule cells following translocation of the soma into an existing apical dendrite. Somatic translocation converts dendritic branches into primary dendrites and shifts adjacent apical dendrites to the basal pole of the cell. Moreover, somatic translocation contributes to the dispersion of the granule cell body layer in vitro, and when granule cell dispersion is induced in vivo, the dispersed cells exhibit virtually identical derangements of their dendritic structures. Together, these findings identify novel forms of neuronal plasticity that contribute to granule cell dysmorphogenesis in the epileptic brain.

\section{Introduction}

The epileptic brain is characterized by numerous alterations in hippocampal granule cell structure, including dispersion of the normally compact granule cell body layer (Houser, 1990), accumulation of cells with dendrites projecting into the hilus (Spigelman et al., 1998), formation of recurrent basal dendrites, which project inappropriately off the basal pole of the cell toward the hilus, but then turn and correctly target the dentate molecular layer (Dashtipour et al., 2002), and a variety of distortions of the dendritic tree (Scheibel and Scheibel, 1973; von Campe et al., 1997). Although many of these aberrant plastic changes were first described decades ago, the cellular processes by which they develop have only recently begun to be elucidated.

To reveal the processes underlying granule cell dysmorphogenesis, organotypic entorhinal-hippocampal cultures were made from Thy1-Yellow fluorescent protein (YFP)-expressing mice. Living granule cells in these explants can be repeatedly imaged with confocal microscopy, and explant preparation alone promotes granule cell hyperexcitability and recapitulates neuroplastic changes observed in the intact epileptic brain (Routbort et al., 1999), providing an opportunity to visualize plastic changes in real time.

\section{Materials and Methods}

Time-lapse imaging of granule cell dendritic plasticity. Organotypic entorhinal-hippocampal explant cultures $(n=27)$ were prepared from 5 - to

Received June 30, 2010; revised Dec. 10, 2010; accepted Dec. 23, 2010.

This work was supported by Cincinnati Children's Hospital Medical Center and the National Institute of Neurological Disorders and Stroke (S.C.D., Award Numbers R01NS065020 and R01NS062806). The content is solely the responsibility of the authors and does not necessarily represent the official views of the National Institute of Neurological Disorders and Stroke or the National Institutes of Health. Thy1-YFP mice were generously provided by Dr. Guoping Feng (Duke University, Durham, NC). We would also like to thank Keri Kaeding, Dr. Chia-Yi Kuan, Dr. Andreas Loepke, and Stefanie Bronson for useful comments on earlier versions of this manuscript.

Correspondence should be addressed to Dr. Steve C. Danzer, 3333 Burnet Avenue, ML 2001, Cincinnati, $\mathrm{OH}$ 45229-3039. E-mail: steve.danzer@cchmc.org.

DOI:10.1523/JNEUROSCI.3381-10.2011

Copyright $\odot 2011$ the authors $\quad 0270-6474 / 11 / 312959-06 \$ 15.00 / 0$ 8-d-old male and female Thy1-YFP-expressing mice on a C57BL/6 background ( $n=20$, H line) (Feng et al., 2000) as previously described (Danzer et al., 2002). All procedures conformed to institutional guidelines for the care and use of animals. Cultures were screened for the presence of YFP-expressing dentate granule cells after 6-7 d in vitro (DIV). Poorly labeled granule cells, granule cells exhibiting degenerative changes, and granule cells obscured by the processes of other cells were excluded. For imaging, explants were placed on the stage of a DMI 6000 microscope encased in a Ludin chamber maintained at $37^{\circ} \mathrm{C}$ and supplied with a humidified 5\% $\mathrm{CO}_{2} / 95 \%$ air mix. Individual granule cells were imaged through their $Z$-depth at 3-5 $\mu \mathrm{m}$ increments using a $10 \times$ objective at $4-5 \times$ optical zoom using a Leica SP5 confocal microscope. Cells were imaged beginning at 6-7 DIV and were reimaged $1 \mathrm{~d}, 2 \mathrm{~d}$, and 5-7 d later. No evidence of phototoxicity was observed. Explants were fixed in $2.5 \%$ paraformaldehyde at 17-18 DIV.

In vitro kainic acid treatment. On the day of neuron selection (6-7 DIV), explants containing one or more granule cells meeting selection criteria were randomly assigned to either kainic acid treatment or vehicle control. For treatment, explants were transferred to new dishes containing either $5 \mu \mathrm{M}$ kainic acid (Sigma Aldrich) dissolved in Stoppini medium (Stoppini et al., 1991) or vehicle (Stoppini medium alone) for $6 \mathrm{~h}$. After $6 \mathrm{~h}$, explants were returned to their original dishes containing conditioned Stoppini medium, and were then transferred to fresh medium 1 h later.

Analysis of confocal time series. Granule cell primary dendrite segment length was quantified from confocal image stacks imported into Neurolucida software (version 7.50.4; MicroBrightField). Granule cell layer dispersion in explants was measured using Leica Application Suite software (1.7.0 build 1240). Briefly, for the first and last images in a time series, a box was drawn with 3-5 granule cells serving as "corners." Corner granule cells were selected from both the inner and outer granule cell layer, so that any spreading of the granule cell layer would be evident as an increase in the box's size. Percentage change was defined as follows: (initial area - final area)/initial area. Notably, this approach does not rely on the assumption that the position of any particular cell is constant over time. Dispersion analyses were conducted on all explants containing morphologically stable granule cells and on all explants exhibiting the formation of a recurrent basal dendrite or a novel primary dendrite. Explants that did not contain at least three "corner" granule cells, however, were excluded from this analysis. 
Double labeling of YFP-expressing granule cells with neuronal age markers. Seventeen cultures $(n=17)$ from seven Thyl-YFP mice were fixed in $2.5 \%$ paraformaldehyde after 7 DIV and immunostained for calretinin (1:1000, MAB1568, Millipore, $n=5)$, calbindin (1:500, C9848, SigmaAldrich, $n=6$ ), or NeuN (1:200 MAB377, Millipore, $n=6$ ). Primary antibodies were visualized using AlexaFluor 647 donkey anti-mouse secondary antibodies (1:750, Invitrogen). Randomly selected YFP-expressing neurons were scored for the presence or absence of each marker.

Intrahippocampal kainic acid injection to induce granule cell dispersion in vivo. Ten-weekold male mice were used for intrahippocampal kainic acid (IHp-KA) injection experiments using established procedures (Bouilleret et al., 1999). Briefly, $60-70 \mathrm{nl}$ of a $20 \mathrm{~mm}$ solution of kainic acid in $0.9 \%$ sterile $\mathrm{NaCl}(1.2-1.4 \mathrm{nmol}$ of kainic acid) was injected into the right dorsal hippocampus of each animal $(1.6 \mathrm{~mm}$ posterior and $1.6 \mathrm{~mm}$ lateral to bregma, $2.0 \mathrm{~mm}$ below dura). Upon recovering from anesthesia, mice were monitored for $8-10 \mathrm{~h}$ for behavioral seizure activity, which was characterized by mild clonic movements of the forelimbs, rotations, and immobility. One $(n=4)$ and two $(n=8)$ weeks after IHp-KA injection, mice were perfused with $2.5 \%$ paraformaldehyde. Uninjected age-matched mice $(n=10)$ were used as naive controls. Control animals were not surgically manipulated to avoid inadvertently disrupting granule cells by trauma alone.

Quantification of dispersed cells in the IHp-KA model. Brain sections between bregma -1.22 $\mathrm{mm}$ and $-2.46 \mathrm{~mm}$ (Paxinos and Franklin, 2001) were immunostained with the granule cell marker Proxl (1:2000, AB5475, Millipore Bioscience Research Reagents) followed by AlexaFluor 647 donkey anti-rabbit secondary antibodies (1:750, Invitrogen). YFP-expressing, Prox1-immunoreactive cells were scored as ectopic if the soma was at least one cell body diameter above the granule cell layer-molecular layer border. Ectopic cells were further scored for the presence of recurrent basal dendrites.

Statistics and data analysis. For all analyses, statistical significance was determined using SigmaStat software (version 11.0). Specific tests were used as noted in the results. Data are presented as means \pm SEM.

Figure preparation. Unless otherwise stated, all images are maximum projections exported as TIFF files and imported into Adobe Photoshop. Some images were adjusted using Leica morphological erosion filter (radius $=3$; iterations $=1$ ) or deconvolution software, as noted. Brightness and contrast of digital images were adjusted to optimize cellular detail. Identical adjustments were made to all images meant for comparison.

\section{Results}

Formation of recurrent basal dendrites by relocation of existing apical dendrites

Analysis of explants paraformaldehyde fixed after 1 week in culture (7 DIV) revealed that culture preparation alone was sufficient to drive recurrent basal dendrite formation. In 7 DIV explants, $20.26 \pm$ $3.66 \%$ of YFP-expressing cells had recurrent dendrites $(n=7$ explants, 136 cells). By contrast, only $2.78 \pm 2.78 \%$ of cells had recurrent basal dendrites in age-equivalent (14-d-old) intact control Thy1-YFP-expressing mice ( $p=0.033, z$ test).

To reveal the cellular processes underlying recurrent basal dendrite formation, 27 explants were serially imaged beginning at $\mu \mathrm{m} ; i-I, 100 \mu \mathrm{m}$.
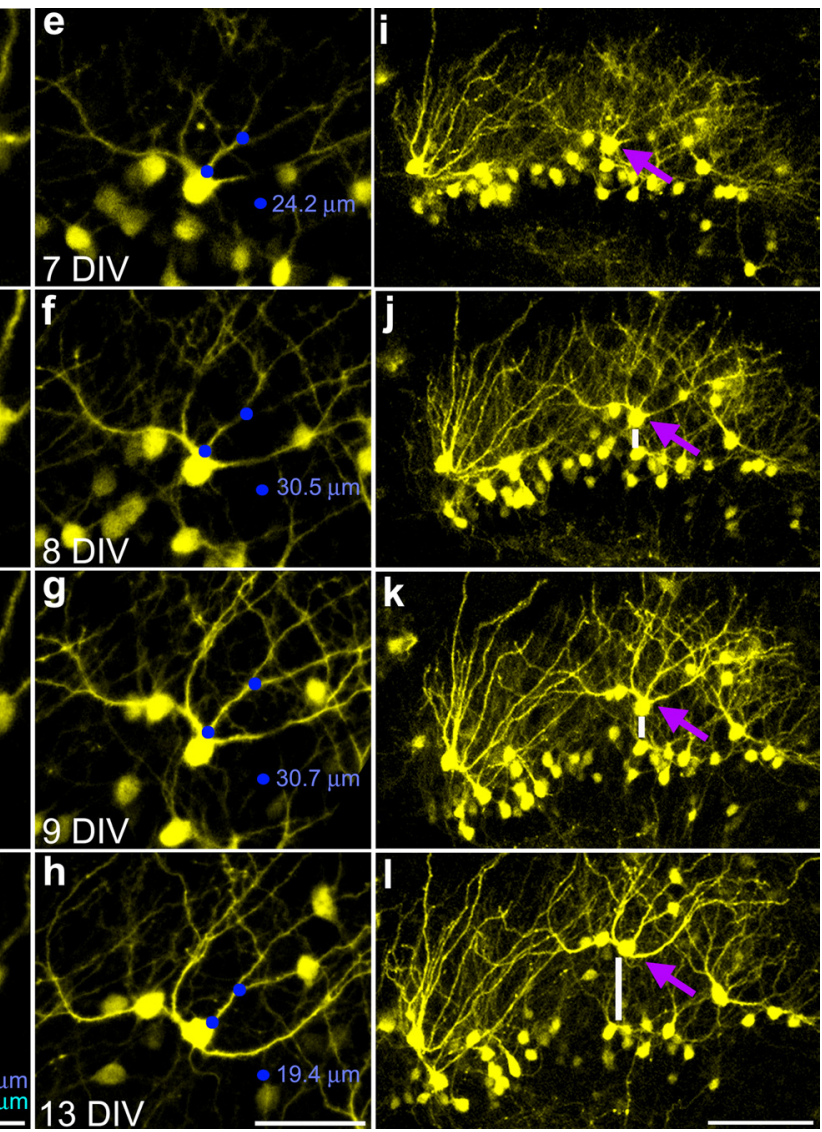

13 DIV

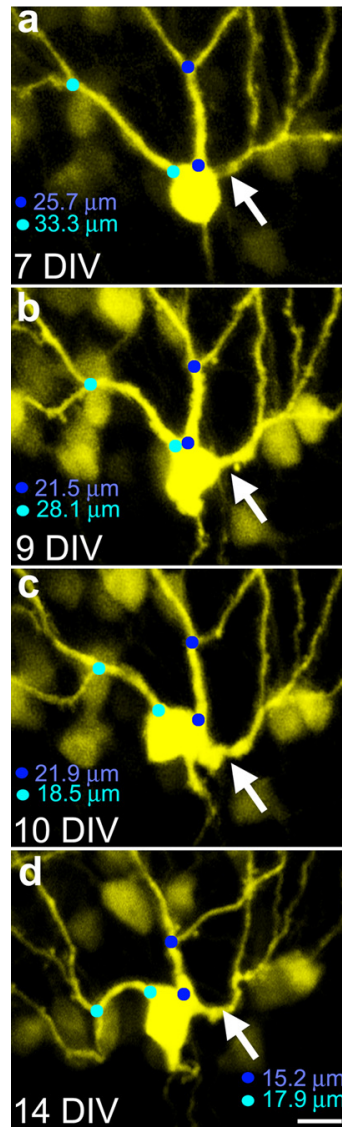

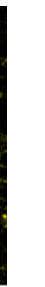

Figure 1. Serial confocal maximum projections of YFP-expressing granule cells showing conversion of apical dendrites into ent basal dendrites. $\boldsymbol{a}-\boldsymbol{d}$, Images taken over 1 week show the formation of a recurrent basal dendrite at 10 DIV (white se granule cell that develops two recurrent basal dendrites at $13 \mathrm{DIV}$. $\boldsymbol{i}-\mathbf{l}$, Images of the granule cell layer containing the cell shown in $\boldsymbol{e}-\boldsymbol{h}$ (purple arrow). Note the simultaneous appearance of recurrent basal dendrites in $\boldsymbol{e}-\boldsymbol{h}$ and granule cell dispersion in $\boldsymbol{i}-\boldsymbol{l}$. The vertical white bar shows movement of the cell of interest away from an initially adjacent cell. Scale bars: $\boldsymbol{a}-\boldsymbol{d}, 10 \mu \mathrm{m} ; \boldsymbol{e}-\boldsymbol{h}, 50$

6-7 DIV. Approximately 40 granule cells expressed YFP in each explant, giving a total of 1030 cells. Forty-three of these cells were selected for analyses (see Materials and Methods), representing $4.2 \%$ of the YFP-expressing cell population. Approximately half of these cultures were also treated with the excitotoxin kainic acid, but as this produced no significant increase in recurrent basal dendrite formation over culture preparation alone (supplemental Table 1, available at www.jneurosci.org as supplemental material), data from all cultures were pooled.

Eight of the forty-three (18.6\%) granule cells examined developed recurrent basal dendrites during the imaging period, revealing for the first time the cellular processes by which this pathology develops. Surprisingly, recurrent basal dendrites were not formed by growth of new dendritic processes from the basal pole of the cell (in fact, no examples of dendritic growth were observed). Rather, existing apical dendrites were observed to shift positions from the apical to the basal pole of the cell (Fig. 1), indicatingquite unexpectedly - that even though these cells are fully differentiated, dendritic origins are not stable relative to the cell body.

\section{Conversion of dendritic branches into primary dendrites}

A second, entirely novel, form of neuronal plasticity observed was the conversion of dendritic branches into primary dendrites. Specifically, secondary dendritic branches moved onto the cell body, 

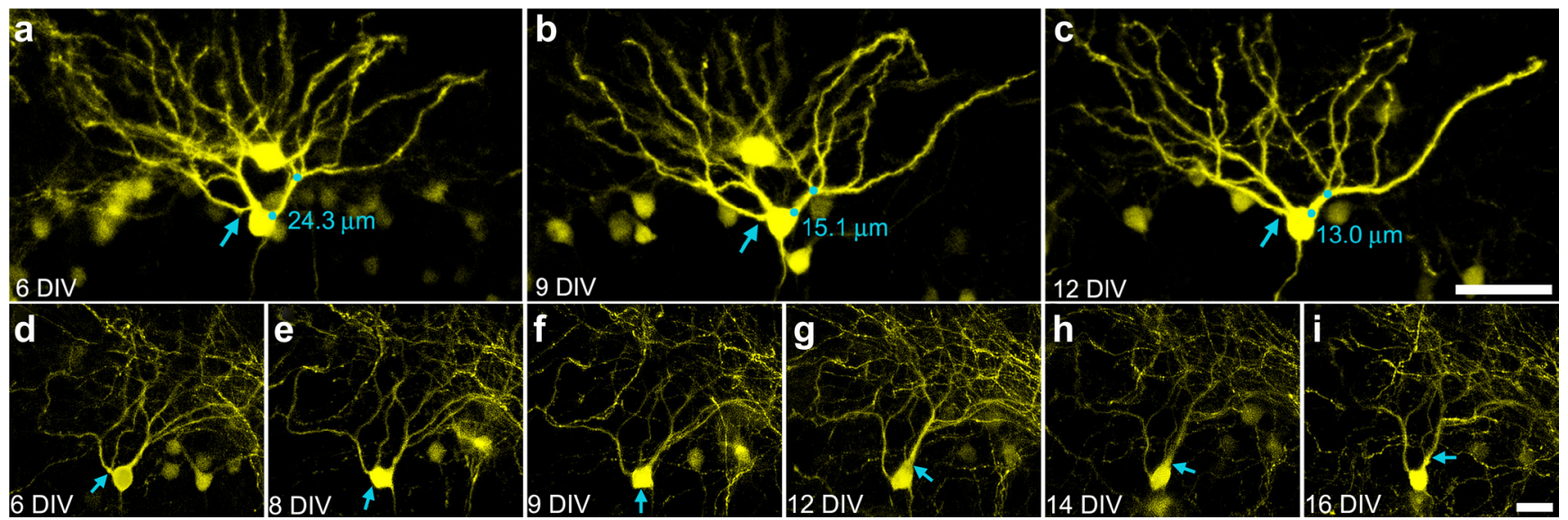

Figure 2. $\boldsymbol{a}-\boldsymbol{c}$, Serial confocal maximum projections of a YFP-expressing dentate granule cell exhibiting conversion of a dendritic branch to a primary dendrite. Images taken over $6 \mathrm{~d}$ exhibit the translocation of a dendritic branch (blue arrow) to the cell body at $9 \mathrm{DIV}$, thus converting it to a primary dendrite. Blue circles denote the length of the primary dendritic segment. Scale bar, $50 \mu \mathrm{m}$. $\boldsymbol{d}-\boldsymbol{i}$, Deconvolved confocal images showing the conversion of a dendritic branch (blue arrow) to a primary dendrite at 8 DIV. Following hypertrophy of the cell body on 12 DIV, the previous dendritic branch — now primary dendrite_-proceeds to move back into position as a dendritic branch, this time, however, on a different dendrite. Scale bar, $25 \mu \mathrm{m}$.

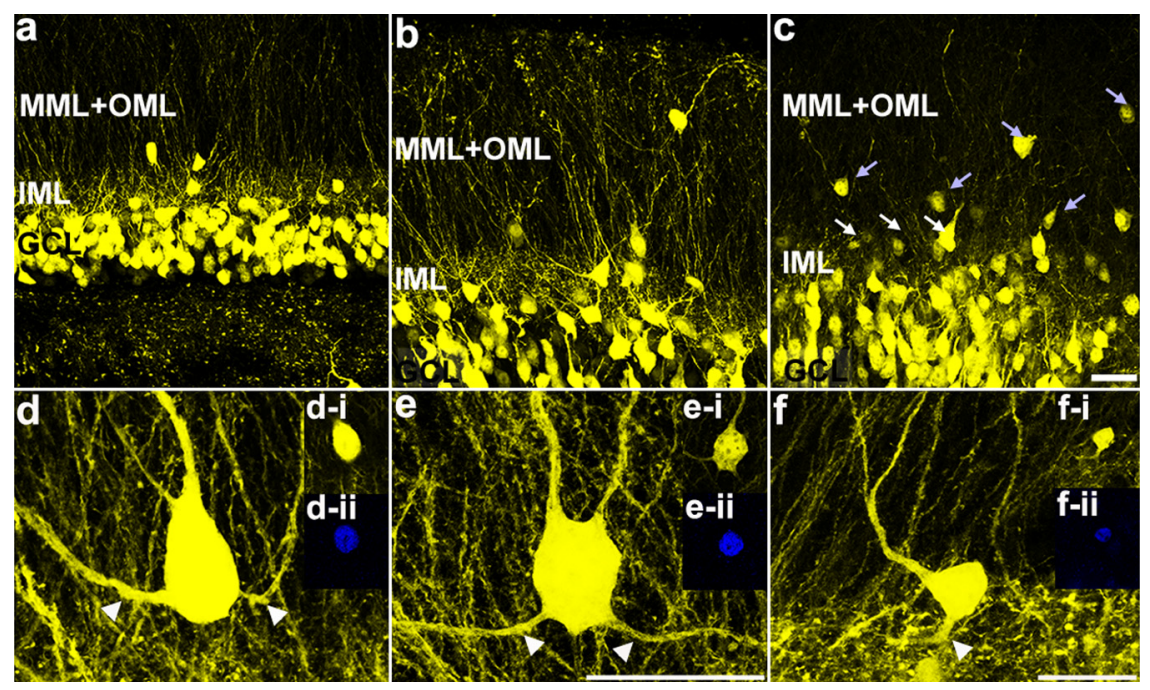

Figure 3. Granule cell dispersion induced by intrahippocampal injection of kainic acid. Confocal maximum projections illustrating the location of the granule cell layer $(\mathrm{GCL})$, inner molecular layer $(\mathrm{IML})$, and outer two-thirds of the molecular layer $(\mathrm{MML}+0 \mathrm{ML})$ in a control mouse $(\boldsymbol{a})$, 1wk-IHpKA mouse $(\boldsymbol{b})$, and 2wk-IHpKA mouse $(\boldsymbol{c})$. Note the greater numbers of ectopic granule cells in the inner (white arrows) and outer (light blue arrows) two-thirds of the dentate molecular layers in the ipsilatera hemisphere of a 2 wk-IHpKA mouse. Scale bar, $30 \mu \mathrm{m}$. $\boldsymbol{d}$-f , Examples of YFP-expressing dentate granule cells with recurrent basal dendrites (white arrowheads) from the ipsilateral hemisphere of IHpKA mice. Granule cells are located in the molecular layer of the dentate gyrus. The insets in $\boldsymbol{d}-\boldsymbol{f}$ are optical sections through the granule cell soma showing the colocalization of $Y F P(\boldsymbol{d}-\boldsymbol{i}, \boldsymbol{e}-\boldsymbol{i}, \boldsymbol{f}-\boldsymbol{i})$ and Prox1 (d-ii, e-ii, f-ii). Scale bars: $\boldsymbol{d}, \boldsymbol{e}$, (in $\boldsymbol{e}), 20 \mu \mathrm{m} ; \boldsymbol{f}, 20 \mu \mathrm{m}$

such that they now became, by definition, primary dendrites (Fig. $2 a-c)$. In the most extreme example observed, a secondary dendritic branch moved its origin to the cell body and existed as a primary dendrite for several days (Fig. $2 d-i$ ). Following swelling and contraction of the cell body, this dendritic branch-now primary dendrite-moved back into position as a dendritic branch, but on a different dendrite. Branch-to-dendrite conversion was observed on 10 of 43 (23.3\%) granule cells (two of these cells also developed recurrent basal dendrites).

\section{Somatic translocation contributes to} dendritic dysmorphogenesis

Careful examination of serial images revealed that, as an apical dendrite shifted to the basal pole of the cell, the primary dendritic segment (the segment between the soma and the first branch point) of an adjacent apical dendrite frequently decreased in length (Fig. 1). To quantify this effect, changes in segment length were determined for the 16 cells exhibiting basal dendrite formation, branch point absorption, or both. Eleven of these cells showed clear decreases in segment length, supporting the conclusion that somatic translocation accounts for the observed dendritic changes.

Based on these measurements, we were able to determine the total movement of the soma over the observation period, the average speed of movement, and the maximum speed. The 11 cells exhibiting clear movement shifted their somata on average $11.04 \pm 1.47 \mu \mathrm{m}$ toward the molecular layer, with the maximum movement observed being $20.45 \mu \mathrm{m}$. Average speed of movement for these cells was $2.20 \pm$ $0.24 \mu \mathrm{m} / \mathrm{d}$, although somatic movement tended to occur in spurts, with a maximum speed observed of $9.6 \mu \mathrm{m} / \mathrm{d}$. It is unclear how dendritic changes developed in the five cells that did not show obvious somatic translocation (including the cell depicted in Fig. $2 d-i$ ). In some cases, the soma appeared to move first toward one dendrite, and then another, complicating interpretation; but the possibility that mechanisms apart from somatic translocation account for some plastic changes should not be discounted.

Granule cell dysmorphogenesis is correlated with cell layer dispersion

Evidence of somatic translocation in the present study raises the possibility that this phenomenon may contribute to granule cell layer dispersion. Dispersion of cell body layers is typical of organotypic hippocampal explants, as cultures thin and spread during the incubation period. To determine whether dendritic dysmorphogenesis was correlated with granule cell dispersion, dispersion in explants containing the most stable granule cells $(n=10)$ (supplemental Fig. 1, available at www.jneurosci.org as supple- 


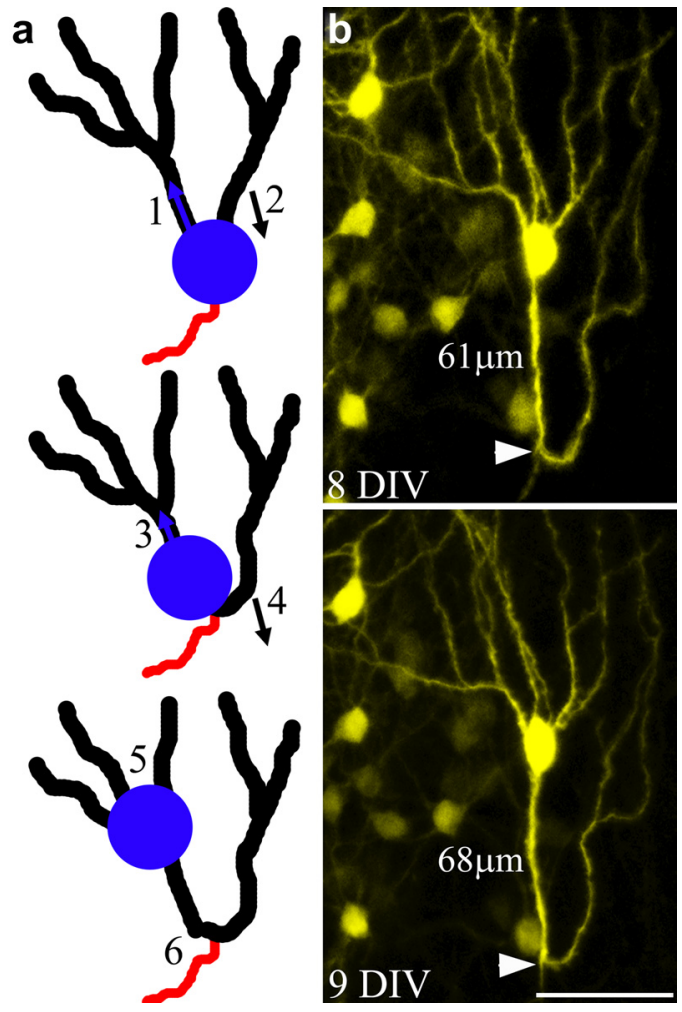

Figure 4. Model depicting granule cell dysmorphogenesis following somatic translocation into an apical dendrite. $\boldsymbol{a}$, As the soma moves into the initial segment of the left apical dendrite (1), the right apical dendrite is "left behind," gradually shifting its position from the apical to the basal pole of the cell (2). Continuation of this process leads to a shortening of the initial dendritic segment on the left (3), and conversion of the right apical dendrite into a recurrent basal dendrite (4). In extreme cases, further migration of the soma leads to the absorption of branch points, converting these structures into primary dendrites (5), and the formation of dendritic loops projecting toward the hilus (6). $\boldsymbol{b}$, An example of a granule cell exhibiting a recurrent basal dendrite with a pronounced dendritic loop and an unusually large number of apical dendrites, the putative end product of the processes outlined in $\boldsymbol{a}$. Note that the axon (white arrowhead) projects off the base of the dendritic loop, suggesting that this was the original location of the cell body. Scale bar, $50 \mu \mathrm{m}$.

mental material) was compared to explants containing cells that exhibited the most dramatic changes $(n=11)$. The latter displayed significantly more dispersion relative to explants containing stable cells (percentage change for explants with disrupted cells, $27.0 \pm 16.3 \%$; stable cells $-3.9 \pm 2.6 \%$; $p=0.007$, MannWhitney rank-sum test).

\section{Granule cell dysmorphogenesis does not reflect acute cellular degeneration}

Cultures were maintained for at least $3 \mathrm{~d}$ after the last liveimaging session to ensure that the plastic changes described here did not reflect terminal degenerative changes. Serial-imaging data revealed a characteristic pattern of granule cell death. Dying cells first exhibited dendritic beading and a diminution of the YFP signal, followed by disintegration of the cell into a series of disconnected YFP-containing compartments (supplemental Fig. 2, available at www.jneurosci.org as supplemental material). This process occurred rapidly, often leaving no evidence of the cell within $24 \mathrm{~h}$. Granule cells appearing to be in any stage of this process at the end of the experiment (3-5 d after the last imaging session) were excluded from the study.

\section{Granule cells exhibiting plastic changes are}

fully differentiated

A subset of explant cultures was immunostained after 7 DIV to assess the developmental stage of YFP-expressing cells. Cultures were immunostained with calretinin, a marker of early postmitotic granule cells; NeuN, a postmitotic neuronal marker; and calbindin, a marker of fully differentiated granule cells [for review of granule cell markers, see Zhao et al. (2008)]. At 7 DIV, 5 of 138 YFP cells $(3.62 \%)$ colocalized calretinin, 127 of 130 YFP cells (97.69\%) colocalized NeuN, and 182 of 202 YFP cells $(90.09 \%)$ colocalized calbindin (supplemental Fig. 3, available at www. jneurosci.org as supplemental material). Morphologically, YFPlabeled cells appeared mature, exhibiting spine-coated dendrites projecting to the hippocampal fissure, somata located throughout the granule cell layer, and axons projecting into the hilus and stratum lucidum. Hilar basal dendrites were absent, as is typical for mature, but not immature, granule cells (Jones et al., 2003; Shapiro and Ribak, 2005).

\section{Migration of granule cells and recurrent basal dendrite formation occur in vivo}

The present study suggests that granule cell dispersion occurs following migration of the soma up a leading apical dendrite, which in turn leads to the formation of recurrent basal dendrites. If correct, granule cell dispersion and recurrent basal dendrite formation should occur in synchrony. To test this prediction, and to explore the cellular mechanisms by which recurrent basal dendrites form in vivo, we used the intrahippocampal kainic acid injection model of epilepsy (IHp-KA). In this model, kainic acid is injected unilaterally into the hippocampus, leading to status epilepticus, epileptogenesis, and granule cell dispersion.

Measures of granule cell dispersion focused on cells located in the dentate molecular layer, as these cells presumably migrated the greatest distances to arrive at this location. The number of granule cells in the molecular layer was significantly increased 1 (1wk-IHpKA) and 2 (2wk-IHpKA) weeks after IHp-KA (Fig. 3) (control, $15.6 \pm 1.4$ ectopic cells/dentate; $1 w \mathrm{k}-\mathrm{IHpKA}, 22.5 \pm$ 2.4; 2 wk-IHpKA, $34.5 \pm 4.6$; ANOVA on ranked data, $p<0.001$ ). The most parsimonious explanation for the appearance of these additional cells is that they migrated from the granule cell body layer to the molecular layer after IHp-KA. We next queried whether granule cells with recurrent basal dendrites were more common in the molecular layer after IHp-KA. The incidence of granule cells with recurrent basal dendrites (Fig. $3 d-f$ ) was increased $1(p=0.025)$ and $2(p=0.035)$ weeks after IHp-KA relative to controls (control, $0.75 \pm 0.29$ ectopic cells with recurrent basal dendrites/dentate; 1wk-IHpKA, $3.25 \pm 0.85$; 2 wkIHpKA, $3.25 \pm 1.07$, ANOVA on ranked data, $p<0.034$ ). Interestingly, between 1 and 2 weeks, the number of cells with recurrent dendrites was stable, although whether this reflects different mechanisms of cell movement, partial recovery of neuronal structure (see Fig. 1c,d), neuronal loss, or other factors is not clear. Importantly, the data demonstrate a positive association between aberrant granule cell migration into the dentate molecular layer and formation of recurrent basal dendrites in the intact brain.

\section{Discussion}

Dysmorphic neurons are present in the dentate gyrus of epileptic animals and humans; however, the neuroplastic mechanisms by which these pathologies develop remain unclear. Here, using real-time imaging of living granule cells in organotypic cultures, we demonstrate that fully differentiated granule cells with ini- 
tially normal morphologies can contort over a period of days, producing dysmorphic neurons remarkably similar to those observed in patients with epilepsy (Scheibel and Scheibel, 1973; von Campe et al., 1997; da Silva et al., 2006). Surprisingly, the process by which these changes evolve revealed two novel forms of neuronal plasticity. First, apical dendrites were observed to shift their origins to the basal pole of the cell. Second, absorption of dendritic branch points by the soma was observed, converting these dendritic branches into primary apical dendrites. Intriguingly, these plastic changes occurred in synchrony with a shortening of apical dendrite initial segments and dispersion of the granule cell layer, suggesting that they were a consequence of somatic movement up a leading apical process. To test this prediction, and to explore the cellular mechanisms by which recurrent basal dendrites form in vivo, we used the IHp-KA model of epilepsy. While any effect of in vitro KA (supplemental Table 1, available at www. jneurosci.org as supplemental material) was likely occluded by the ability of explant preparation alone to induce granule cell dispersion, in vivo KA produced robust granule cell dispersion relative to controls. Morphological analysis of dispersed cells, which moved into the dentate molecular layer, revealed that they exhibited the same types of dendritic anomalies observed evolving in vitro. This suggests that they also migrated to their new positions by somatic movement up a leading apical process.

\section{Somatic translocation leads to granule cell dispersion and dendritic dysmorphogenesis}

In the present study, apical dendrites shifted to the basal pole of the cell, dendritic branches became apical dendrites, and granule cell bodies moved radially away from each other. One phenomenon that could account for all these plastic changes is translocation of the granule cell soma into an apical dendrite. In the model depicted in Figure 4, somatic translocation would lead to the shortening of dendritic initial segments, and in extreme cases, branch point absorption. Continued movement of the soma up an apical dendrite would gradually shift adjacent dendrites that are "left behind" to the basal pole of the cell, while simultaneously displacing the soma into the dentate molecular layer. No other single cellular process can account for all of these plastic changes, leading us to conclude that some form of somatic translocation is occurring.

\section{Somatic translocation of fully differentiated neurons}

Somatic translocation is a principal migratory mechanism of the developing CNS and occurs when the nucleus and perisomatic cytoplasm are displaced into a leading process (Rakic, 1972, Métin et al., 2008). Typically, only immature neurons migrate. YFPexpressing granule cells in the present study, however, were fully differentiated, corresponding to stage 6 of neuronal development in adult mammals (supplemental Fig. 3, available at www. jneurosci.org as supplemental material) (Kempermann et al., 2004). Somatic translocation has not been previously described among fully differentiated granule cells. It is clear, however, that they can shift position in vivo. Previous studies using the IHp-KA model of epilepsy have revealed that movement of mature granule cells underlies dispersion into the dentate molecular layer (Heinrich et al., 2006; Nitta et al., 2008). By contrast, accumulation of ectopic granule cells in the dentate hilus results from the aberrant migration of immature granule cells (Walter et al., 2007). These cells do not express YFP in the Thyl line used here, and no YFP-expressing cells were observed moving into the hilus, consistent with findings that only immature cells migrate in this direction. Although unusual, migration of differentiated neurons is not entirely unprecedented, with the demonstration by Morozov et al. (2006) that a class of hippocampal interneuron can migrate while maintaining previously generated synaptic connections.

\section{Possible mechanisms of somatic translocation}

Cell movement during neuronal migration is a three-step process, beginning with the extension of a leading process, followed by somatic translocation into that process and ending with retraction of the trailing process (Marín et al., 2010). In this context, the movement observed here is atypical. Movement of the soma is apparent, but extension of a leading process is lacking, and there is a clear failure to retract the trailing process (Fig. $4 b$ ). These observations suggest that movement of differentiated granule cells relies solely on nucleokinesis. This incomplete activation of cell migratory process may account for the slow rate of movement observed in the present study (tens of micrometers per day) relative to normal cell migration (tens of micrometers per hour).

In perhaps the best described mechanism of nucleokinesis, the centrosome and Golgi apparatus take position in the leading process ahead of the nucleus. The centrosome remains connected to a microtubule cage surrounding the nucleus, and microtubulebased motor proteins are able to pull the perinuclear cage forward (Métin et al., 2008). The centrosome's placement in the leading process creates a swelling visible with light microscopy. Although convincing evidence for such swellings was not present in our images, these swellings can appear and disappear in minutes, and would be difficult to capture reliably without virtually continuous monitoring.

Nuclear movement can also be driven by actin and myosin II dynamics, creating both pushing and pulling forces. Studies of cerebellar granule cells by He et al. (2010) found pulling forces to be dependent on F-actin dynamics in the leading process-evident microscopically as a motile growth cone-like structure. Such structures, however, were not observed here, implying that pulling forces, if operative, act by other mechanisms. Pushing forces, on the other hand, can be generated by actomyosin contraction at the rear of the cell (Martini and Valdeolmillos, 2010). Indeed, pushing forces, acting in the absence of directional pulling forces, might account for the slow rate of movement and the apparent "indecisiveness" of some somas, which migrated first toward one dendrite and then another. Whether these speculations are correct or not remains to be determined, but clearly studies of actin and microtubule dynamics will be important avenues to address with respect to granule cell dispersion and dendritic remodeling in the hippocampus.

\section{References}

Bouilleret V, Ridoux V, Depaulis A, Marescaux C, Nehlig A, Le Gal La Salle G (1999) Recurrent seizures and hippocampal sclerosis following intrahippocampal kainate injection in adult mice: electroencephalography, histopathology and synaptic reorganization similar to mesial temporal lobe epilepsy. Neuroscience 89:717-729.

Danzer SC, Crooks KR, Lo DC, McNamara JO (2002) Increased expression of brain-derived neurotrophic factor induces formation of basal dendrites and axonal branching in dentate granule cells in hippocampal explant cultures. J Neurosci 22:9754-9763.

Dashtipour K, Yan XX, Dinh TT, Okazaki MM, Nadler JV, Ribak CE (2002) Quantitative and morphological analysis of dentate granule cells with recurrent basal dendrites from normal and epileptic rats. Hippocampus $12: 235-244$

da Silva AV, Houzel JC, Targas Yacubian EM, Carrete H Jr, Sakamoto AC, Priel MR, Martins HH, Oliveira I, Garzon E, Stavale JN, da Silva Centeno 
R, Machado H, Cavalheiro EA (2006) Dysmorphic neurons in patients with temporal lobe epilepsy. Brain Res 1072:200-207.

Feng G, Mellor RH, Bernstein M, Keller-Peck C, Nguyen QT, Wallace M, Nerbonne JM, Lichtman JW, Sanes JR (2000) Imaging neuronal subsets in transgenic mice expressing multiple spectral variants of GFP. Neuron 28:41-51.

He M, Zhang ZH, Guan CB, Xia D, Yuan XB (2010) Leading tip drives soma translocation via forward F-actin flow during neuronal migration. J Neurosci 30:10885-10898.

Heinrich C, Nitta N, Flubacher A, Müller M, Fahrner A, Kirsch M, Freiman T, Suzuki F, Depaulis A, Frotscher M, Haas CA (2006) Reelin deficiency and displacement of mature neurons, but not neurogenesis, underlie the formation of granule cell dispersion in the epileptic hippocampus. J Neurosci 26:4701-4713.

Houser CR (1990) Granule cell dispersion in the dentate gyrus of humans with temporal lobe epilepsy. Brain Res 535:195-204.

Jones SP, Rahimi O, O’Boyle MP, Diaz DL, Claiborne BJ (2003) Maturation of granule cell dendrites after mossy fiber arrival in hippocampal field CA3. Hippocampus 13:413-427.

Kempermann G, Jessberger S, Steiner B, Kronenberg G (2004) Milestones of neuronal development in the adult hippocampus. Trends Neurosci 27:447-452.

Marín O, Valiente M, Ge X, Tsai LH (2010) Guiding neuronal cell migrations. Cold Spring Harb Perspect Biol 2:a001834.

Martini FJ, Valdeolmillos M (2010) Actomyosin contraction at the cell rear drives nuclear translocation in migrating cortical interneurons. J Neurosci 30:8660-8670.

Métin C, Vallee RB, Rakic P, Bhide PG (2008) Modes and mishaps of neuronal migration in the mammalian brain. J Neurosci 28:11746-11752.

Morozov YM, Ayoub AE, Rakic P (2006) Translocation of synaptically connected interneurons across the dentate gyrus of the early postnatal rat hippocampus. J Neurosci 26:5017-5027.
Nitta N, Heinrich C, Hirai H, Suzuki F (2008) Granule cell dispersion develops without neurogenesis and does not fully depend on astroglial cell generation in a mouse model of temporal lobe epilepsy. Epilepsia 49: 1711-1722.

Paxinos G, Franklin KBJ (2001) The mouse brain in stereotaxic coordinates. San Diego: Academic.

Rakic P (1972) Mode of cell migration to the superficial layers of fetal monkey neocortex. J Comp Neurol 145:61-83.

Routbort MJ, Bausch SB, McNamara JO (1999) Seizures, cell death, and mossy fiber sprouting in kainic acid-treated organotypic hippocampal cultures. Neuroscience 94:755-765.

Scheibel ME, Scheibel AB (1973) Hippocampal pathology in temporal lobe epilepsy: a Golgi survey. In: Epilepsy: its phenomena in man (Brazier MAB, ed), pp 311-337. New York: Raven.

Shapiro LA, Ribak CE (2005) Integration of newly born dentate granule cells into adult brains: hypotheses based on normal and epileptic rodents. Brain Res Brain Res Rev 48:43-56.

Spigelman I, Yan XX, Obenaus A, Lee EY, Wasterlain CG, Ribak CE (1998) Dentate granule cells form novel basal dendrites in a rat model of temporal lobe epilepsy. Neuroscience 86:109-120.

Stoppini L, Buchs PA, Muller D (1991) A simple method for organotypic cultures of nervous tissue. J Neurosci Methods 37:173-182.

von Campe G, Spencer DD, de Lanerolle NC (1997) Morphology of dentate granule cells in the human epileptogenic hippocampus. Hippocampus 7:472-488.

Walter C, Murphy BL, Pun RYK, Spieles-Engemann AL, Danzer SC (2007) Pilocarpine-induced seizures cause selective time-dependent changes to adult-generated hippocampal dentate granule cells. J Neurosci 27: 7541-7552.

Zhao C, Deng W, Gage FH (2008) Mechanisms and functional implications of adult neurogenesis. Cell 132:645-660. 